\title{
La preocupación médica y religiosa del doctor Pedro López por las personas de raza negra de la ciudad de México (1582-1597) ${ }^{1}$
}

\author{
Luis Martínez Ferrer
}

Universidad Pontificia de la Santa Cruz, Roma

El artículo trata de la actividad caritativa y asistencial que el médico español Pedro López (1582-1597) desarrolló con la población de color en la ciudad de México. Tras un esbozo biográfico de López, se presenta la situación jurídica y social de negros y mulatos en la urbe mexicana en la segunda mitad del siglo XVI. A continuación se describen dos iniciativas de López hacia los negros: la fundación del hospital de los Desamparados (1582) y la petición al Tercer Concilio de México (1585) del permiso para crear una cofradía de negros y negras en la capital de Nueva España.

Palabras Clave: México, siglo XVI, hospitales, negros, mulatos, concilio, cofradía, caridad.

The article deals with the charitable care and assistence carried out by the Spanish physician Pedro López (1582-1597) with the non-white population in Mexico City. After a biographical sketch of López, the juridical and social situation of blacks and mulattos in Mexico City in the second half of the $16^{\text {th }}$ century is presented. Then two of López's initiatives on behalf of the blacks are described: the founding of the hospital of the Desamparados (1582), and the request to the Third Council of Mexico (1585) for permission to create a confraternity of black men and women in the capital of New Spain.

Keywords: Mexico. 16 $6^{\text {th }}$ century. Hospitals. Blacks. Mulattos. Council. Confraternity. Charity.

El grupo de personas de color en la ciudad de México a fines del siglo XVI no constituía en absoluto un colectivo marginal. Aguirre Beltrán calculó que en 1570 había en el arzobispado de México 11.736 africanos y 2.000 mestizos. $^{2}$ Hacia ese grupo se dirigió el doctor Pedro López con tres

1 Agradezco sentidamente a la Fundación Glaxo Smith Kline, en la persona del Doctor Marco Aurelio Botey, su ayuda económica para realizar esta investigación. Mi profundo reconocimiento a diversos colegas que me han alentado con su colaboración y consejos: M. ${ }^{a}$ Concepción Amerlink, del Instituto Nacional de Antropología e Historia (INAH) en la ciudad de México, Alicia Bazarte, del Instituto Politécnico Nacional de México, Alberto Carrillo Cázares y Nora Reyes, del Colegio de Michoacán, Jesús Joel Peña, del INAH de Puebla de los Ángeles, y Carlos Viesca, de la Academia Nacional de Medicina de México.

2 Aguirre Beltrán, Gonzalo: La población negra en México, Fuente Cultural, México, 1946, pág. 213. 
iniciativas: el Hospital de los Desamparados (fundado en 1582), las conferencias cuaresmales de 1585 y los memoriales a los padres del Tercer Concilio de México para que los negros tuvieran una cofradía. Antes de pasar al estudio de estas iniciativas de López es necesario presentarlo.

\section{El doctor Pedro López ${ }^{3}$}

Pedro López nació hacia 1527 en la villa de Dueñas, en Palencia, pasando a México muy joven. Conocemos el nombre de su mujer, Juana de León, y de tres de sus hijos: José, que fue cura de la catedral mexicana, Agustín y Nicolás. En 1585, en un memorial dirigido a los conciliares del Tercer Concilio Mexicano, afirmaba el doctor López que "va para treinta y cinco años que estoy en esta tierra". ${ }^{4}$ El 2 de agosto y el 3 de septiembre de 1553 obtuvo los grados de Licenciado y Doctor en Medicina en la Universidad de México. ${ }^{5}$ Destaca su empeño en la fundación de hospitales en la capital del virreinato, siendo.concretamente dos los institutos hospi-

3 Cfr. la pequeña biografía de Somolinos d'Ardois, Germán: Capítulos de historia médica mexicana, vol. III: Relación alfabética de los profesionistas médicos, o en conexión con la medicina, que practicaron en territorio mexicano (1521-1618), Sociedad Mexicana de Historia y Filosofía de la Medicina, México s.f., págs. 249-253. Otras semblanzas de este personaje: Cabrera y Quintero, Cayetano: Escudo de armas de México, Impreso en México por la Viuda de Don Joseph Bernardo de Hogal, México, 1746 (referencias a Pedro López, págs. 812-814, 857); Franco, Fray Alonso: Segunda parte de la Historia de la Provincia de Santiago de México, orden de Predicadores, Imprenta del Museo Nacional, México, 1900 (referencias en lib. 1, cap. 37); García Icazbalceta, Joaquín: "Los médicos de México en el siglo XVI", en Ibidem, Biografias. Estudios, Porrúa, México, 1998 (sobre Pedro López, págs. 320-321); Greenleaf, Richard E: ““Padre de los Pobres”: Dr. Pedro López of Sixteenth-Century Mexico", Colonial Latin American Historical Review (CLAHR), 8/3, Albuquerque, 1999, págs. 257-271; Ferreiro, Natalia y Nelly Sigaut: “Testamento del 'fundador’ Dr. Pedro López. Documentos para la historia del Hospital de San Juan de Dios”, Historia Mexicana, 217, México, 2005, págs. 145-201; en su momento compartí diversa información manuscrita personal con la doctora Ferreiro, como ella misma declara en su artículo conjunto con Sigaut, donde vengo citado en diversas ocasiones.

4 Bancroft Library (Berkeley), Mexican Manuscripts [en adelante MM], 268, fol. 234r; con posterioridad a mi investigación, basada en los manuscritos originales, Alberto Carrillo ha publicado una excelente edición: Manuscritos del Concilio Tercero Provincial Mexicano (1585), edición, estudio introductorio, notas, versión paleográfica y traducción de textos latinos por Alberto Carrillo Cázares (Mexican Manuscripts 268, The Bancroft Library), El Colegio de Michoacán- Universidad Pontificia de México, Zamora, Mich., 2006, Tomo I, pág. 419. Para comodidad de los lectores, citamos primero el folio manuscrito, y luego la página de la edición de Carrillo. Hemos optado por modernizar el castellano.

5 Si son ciertos estos datos (véase "López, Pedro", en Diccionario Porrúa de Historia, Biografía y Geografía de México, Porrúa, México, 1995, pág. 2031) significa que la Universidad de México, que inició sus cursos en enero del 1553, convalidó rápidamente los estudios de López. 
talarios surgidos por su iniciativa. En 1572, tras conseguir la licencia del arzobispo Montúfar, abrió sus puertas el hospital de San Lázaro, dedicado a los leprosos de todas las categorías sociales. Como explica un informe de 1583, "fundóse con industria e instancia del doctor Pero López, médico, persona devota, cristiana y caritativa, con limosnas que ha pedido y recogido para este efecto en esta ciudad y arzobispado, con las cuales se sustentan, acudiendo el dicho doctor a la cura de los enfermos con mucho cuidado y a hacerles proveer de todo lo necesario [...] Dice misa en el dicho hospital el maestro José López, hijo del dicho doctor". ${ }^{6}$ Se trataba de un "hospital nacional", pues era el único especializado en leprosos -por otra parte más bien escasos- de toda Nueva España. Don Pedro y su mujer fueron los patronos fundadores $\mathrm{y}$, a la muerte del primero, en la ciudad de México en 1597, sus hijos se ocuparon de la cobertura económica del hospital. El segundo centro hospitalalario fundado por nuestro personaje fue el inicialmente llamado de la Epifanía (1582), del que nos ocuparemos más adelante. Fue gran amigo de las órdenes religiosas, particularmente de los dominicos, a quienes atendía profesionalmente.

\section{Los negros y mulatos de la ciudad de México (1570-1600) ${ }^{7}$}

Los africanos, traídos masivamente a Nueva España desde los años cuarenta, constituían, inseparablemente unidos a los mulatos, el segundo grupo étnico del Virreinato, muy por delante de los europeos. Aguirre Beltrán nos ofrece estas cifras del año 1570 referidas sólo al arzobispado de México: europeos (2.794), africanos (11.736), indígenas (1.310.904), euro-mestizos (8.632), indo-mestizos (1.992) y afro-mestizos (2.000). ${ }^{8}$ En

6 "Relación de los hospitales de la ciudad y del arzobispado de México, hecha por orden del Arzobispo don Pedro Moya de Contreras. México, 4 de abril de 1583", en Cuevas, Mariano: Documentos inéditos de siglo XVI, Porrúa (Biblioteca Porrúa, 62), México 1975, pág. 326.

7 Además de la bibliografía citada, remitimos a los siguientes estudios bibliográficos: Moedano Navarro, Gabriel: "Bibliohemerografía histórica y etnohistórica sobre la población de origen africano en México", en Pérez-Rocha, Emma y Gabriel Moedano Navarro: Aportaciones a la investigación de archivos del México colonial y a la bibliohemerografía afroamericanista, INAH, México, 1992, págs. 37-64; Chávez Carbajal, María Guadalupe (coord.): El rostro colectivo de la nación mexicana, sección "El panorama historiográfico de los estudios afromexicanistas", con los trabajos de Francisco J. Fernández Repetto, Genny M. Negroe Sierra, Álvaro Ochoa Serrano, Juan M. de la Serna H. y Vicenta Cortés Alonso, Universidad Michoacana de San Nicolás de Hidalgo/INAH, Morelia, Mich., 1997, págs. 157-232.

8 Aguirre Beltrán, La población, pág. 213. 
los años ochenta el auge económico hizo que los precios de los esclavos africanos subieran y su número aumentara. ${ }^{9}$

En la ciudad, los esclavos negros y mulatos tenían diversas ocupaciones. Muchos eran sirvientes domésticos y se desempeñaban como mayordomos, amas de llaves, cocineras, caballerizos, mozos y criados. También en los reinos peninsulares de España abundaban los esclavos domésticos de raza negra; $\sin$ ir más lejos, la propia familia de Pedro López los tenía: cuando en 1554 se disponía a pasar a Indias la esposa de López, Juana de León, en la documentación del Archivo de Indias se habla de permitir el pasaje a "un negro y una negra para el servicio". ${ }^{10}$ Otros muchos trabajaban en comercios o talleres, o eran aprendices en variados oficios: cocheros, zapateros, tejedores, panaderos, herreros, lavanderos, capataces, cargadores, carpinteros, canteros, músicos. Sus maestros solían ser españoles, a veces religiosos e incluso nobles indígenas.

Aunque son muy conocidas, conviene señalar tres distinciones en este colectivo étnico-social: negros "ladinos", "bozales" y "criollos", términos que emplea López en sus escritos. En general se puede entender por ladinos a los esclavos veteranos en Nueva España que conocían el castellano, muchos ya con un oficio. Muy cercana a esta categoría están los "criollos", personas de raza negra nacidas en España, Portugal o América, más apreciados en los mercados. Por el contrario, el grupo de los bozales lo constituían los originarios de África, con grandes problemas para comunicarse en castellano.

Otra distinción fundamental es la de negros esclavos y negros libres pues, como veremos, Pedro López se dedicó principalmente a los segundos. No podemos cuantificar con precisión el número de negros y mulatos libres de la ciudad de México en los años 70/80/90 del Quinientos, pero las menciones en la documentación y las propias acciones respecto a ellos de Pedro López nos llevan a pensar que se trataba de un grupo ciertamente

9 Quizás también por la caída demográfica de los negros debido a la epidemia del cocoliztle de 1576, especie de síntesis de varias enfermedades que diezmó las poblaciones mexicanas.

10 "Probanza del bachiller Agustín López para el Consejo de Indias (19 de febrero de 1554), en Archivo General de Indias, Sevilla [AGI], Indiferente General, 2048, n. 39. Pedro López se había casado con Juana de León en Palencia en torno a 1547. Poco después partiría él para Indias. En esta probanza, el hermano Agustín, bachiller, pide al Consejo de Indias el traslado a Nueva España de Juana de León, junto con diversas personas, entre las que se encuentran estos dos negros. Parece que al final los africanos no debieron hacer la travesía, puesto que el 26 de noviembre de 1554 se despacha una cédula dando permiso para que pase Juana de León con su hermano Diego, y otros dos hombres casados, y se hace referencia sólo a un criado, sin especificar si es negro o no (véase AGI, Indiferente General, 1965, L.12, f. 264v). 
numeroso, aunque muy inferior al de los de condición esclava. Para 1574, Aguirre Beltrán nos informa de un documento de Registro de mulatos y mulatas, esclavos libres que son en esta ciudad de México, recogiendo: 127 mulatos libres, 302 mulatas libres, 26 negros libres y 43 negras. En total 498 personas. $^{11}$

Como bien puede imaginarse, la situación socioeconómica de este grupo de negros y negras libres era muy inestable. La legislación sobre este colectivo ofrece un contraste entre deseos de progreso social y graves preocupaciones. En 1587 una real cédula prescribe que los mulatos y negros libres deben percibir su justo salario ${ }^{12}$ y en 1598 otra cédula les conmina a pagar el tributo al rey. ${ }^{13}$

Sin embargo, la mayoría de las apariciones de los negros y mulatos libres en la documentación son de tipo restrictivo. En 1585, el Cabildo secular de la ciudad de México estaba preocupado sobre si permitir o no a las personas de raza negra que fueran armados a las fiestas de San Hipólito. ${ }^{14}$ Una real cédula de 1587 se refiere a los excesos en sus fiestas y a que algunos portan armas ${ }^{15}$ y de nuevo, dos años después, otra cédula vuelve a repetir la negación de permiso para llevar armas, prohibiendo la reunión de negros en grupos de más de cuatro personas. ${ }^{16}$

Otro elemento importante que debemos considerar para enmarcar las actividades de Pedro López es el de la atención sanitaria, que era muy distinta según se tratase de esclavos o de libres. Las negras y negros esclavos gozaban de cobertura médica a cargo de sus amos. A título de ejemplo, en 1553 el español Francisco Gómez Carrasco recibe al negro Jorge, esclavo,

11 Aguirre Beltrán, La población, pág. 212. Para la ciudad de Puebla, sabemos que existían negros libres desde la década de 1520; Paredes Martínez, Carlos y Blanca Lara Tenorio: "La población negra en los valles centrales de Puebla: orígenes y desarrollo hasta 1681", en Martínez Montiel, Luz M. (coord.): Presencia africana en México, CONACULTA, México, 1994, pág. 65.

12 Archivo General de la Nación (México) [AGNM], Reales Cédulas, vol. 3, exp. 20, f. 10v. Real cédula (31 de agosto de 1587), sobre salarios que se deben dar a mulatos y negros libres que trabajan en haciendas de ganado.

13 Ibidem, vol. 3, exp. 182, f. 156v. Real cédula (30 de junio de 1598), sobre que los negros y mulatos libres deben pagar tributo al rey.

14 Libro noveno de Actas de Cabildo que comenzó en $1^{\circ}$ de enero de 1585 y terminó en 21 de mayo de 1590, Imprenta y Librería de Aguilar e Hijos, México, 1895, pág. 46.

15 AGNM, Reales Cédulas, vol. 3, exp. 28, f. 14. Real cédula (21 de octubre de 1587), sobre esos excesos de negros y mulatos, y que algunos portan armas.

16 Ibidem, vol. 3, exp. 99, f. 61v. Real cédula (18 de septiembre de 1589), sobre que los negros no deben portar armas, ni reunirse en grupos de más de cuatro. A este respecto, hay que señalar que, aunque la última revuelta de negros había sido en 1549, las autoridades no deseaban bajar la guardia permitiendo grupos potencialmente peligrosos. 
al que le enseñará el oficio de zapatero "y si estuviere malo le curaré -dicey pagaré médico y medicina a mi costa". ${ }^{17}$ No ocurría así con los negros y mulatos libres, que debían cuidar de su salud autónomamente.

A esta situación inestable y muchas veces conflictiva hay que añadir los efectos devastadores de la epidemia de cocoliztle de 1576. Así nos refleja su impacto en la ciudad de México el cronista indígena Domingo Chimalpáhin, quien dice que "murieron principalmente los naturales y los negros, pero de los españoles sólo unos cuantos". ${ }^{18}$ Entre la población de origen africano, pensamos que serían los negros libres los que sufrirían con el cocoliztle un impacto mayor.

Por lo que se refiere a la asistencia espiritual de las personas de raza negra de ambos sexos, la sociedad novohispana, igual que la española o la portuguesa de la Península, tenían muy claro que los negros y negras eran también seres humanos destinatarios de la evangelización, y que tenían que ser bautizados; debían conducirse como fieles cristianos y tenían derecho a ser instruidos religiosamente y a recibir los sacramentos. A este respecto, hay varias cédulas de Carlos V y Felipe II que fueron recogidas tanto en la Recopilación de León Pinelo de 1635, que quedó inédita, como en la oficial de 1680. En una ley incluida por León Pinelo se dispone que los prelados seculares o regulares "tengan particular cuidado de la conversión y doctrina de los negros esclavos y de mulatos que hubiere en sus diócesis para que vivan cristianamente y que se tenga en ello la misma orden que se tiene en la conversión y doctrina de los indios". ${ }^{19}$

La ley siguiente se refiere a que, tanto indios como negros, así esclavos como libres, debían oír la doctrina cristiana. Si se trataba de negros en servicio doméstico, debían acudir diariamente a la catequesis pero, en caso de negros empleados en los campos, su instrucción se restringía a los domingos y fiestas de guardar, procurando no entorpecer sus deberes para con los amos. ${ }^{20}$ Pensamos que estas dos leyes no indican la realidad de lo

17 Mondragón Barrios, Lourdes: Esclavos africanos en la Ciudad de México. El servicio doméstico durante el siglo XVI, Ediciones Euroamericanas/Consejo Nacional Para la Cultura y las Artes (CONACULTA)/INAH, México, 1999, pág. 52.

18 Chimalpáhin, Domingo: Diario, paleografía y traducción de Rafael Tena, CONACULTA, México, 2001, pág. 25. Original en náhuatl, pág. 24.

19 León Pinelo, Antonio de: Recopilación de las Indias, 1635, Ley 13, Título 1, Libro 1 (Carlos V, 25 de octubre de 1538, Felipe II, 3 de diciembre de 1579 y 18 de octubre de 1569), ed. de Ismael Sánchez Bella, Miguel Ángel Porrúa, México, 1992, vol. I, pág. 77. Esta ley, junto con la siguiente de León Pinelo, pasó a la Recopilación de 1680 como Ley 9, Libro 1, Título 1.

20 Recopilación de las Indias, 1635, Ley 10, Título 1, Libro 1 (Carlos V, 30 de noviembre de 1537, Felipe II, 25 de mayo de 1596), pág. 77. En la Recopilación de 1680 es la Ley 12, Libro 1, Título 1. 
que se hacía, pero sí la voluntad del poder civil por conseguir la cristianización de los africanos en Indias.

Naturalmente, no era el doctor López el único en Nueva España en preocuparse por la evangelización de los negros. Entre otros, destacan los jesuitas, llegados a México en 1572. Algunas fuentes de la Compañía nos hablan de la enseñanza de la doctrina a negros en la capital del virreinato en $1573^{21}$ y $1579 .{ }^{22}$ Resulta muy significativa una carta annua ${ }^{23}$ sobre la labor jesuítica del año 1580 en la que, al referirse a la predicación a los negros (aetiopum gregi), señala que su número en la ciudad de México era muy notable (quorum haec urbe scatet multitudine). ${ }^{24}$

Con estos puntos de referencia, ${ }^{25}$ podemos ya acometer la presentación de las diversas iniciativas de Pedro López relativas a las personas de raza negra de la ciudad de México: el hospital de los Desamparados de 1582 y sus peticiones al Tercer Concilio de México de 1585.

\section{El Hospital de los Desamparados}

Diez años después de poner en marcha el Hospital de San Lázaro para leprosos, el doctor López decidió iniciar una nueva fundación asistencial. Bien pudiera ser que la gran peste de cocoliztle de 1576 , ya mencionada, fuera el detonante de esta iniciativa, aprobada por el virrey conde de la Coruña y por el arzobispo Moya de Contreras en mayo de $1582 .{ }^{26}$ En el testamento de Pedro López, fechado el 14 de marzo de 1596, podemos leer con claridad cuál fue el espíritu con que llevó a cabo esta empresa:

"Declaro que a gloria de Dios y de su bendita Madre, yo he edificado otra casa y hospita ${ }^{27}$ que se llama de los Desamparados, porque se recogen en ella tres géneros de gentes que en ningún hospital los querrán curar, que son mestizos, mulatos y negros

21 "Carta del P. Pedro Sánchez al General Everardo Mercuriano, México, 8 de marzo de 1573”, en Zubillaga, Félix (ed.): Monumenta Mexicana, vol. I, (Monumenta Historica Societatis Iesu, 77), Roma, 1956, pág. 71.

22 “Carta annua, México, 17 marzo de 1579”, en Monumenta Mexicana, vol. I, pág. 437.

23 Cartas anuales que los diversos colegios de la Compañía enviaban al Prepósito general de Roma, narrando los principales frutos del apostolado. Sus fines eran de mutua edificación.

24 "Carta annua, México anno 1580 exeunte", en Monumenta Mexicana, vol. I, pág. 557.

25 Dejamos para más adelante la confusa cuestión de las cofradías de negros en la época de Pedro López.

26 AGNM, Tierras, vol. 3.556, exp. 4, f. 1r.

27 La otra casa es la de San Lázaro para leprosos, de la que habla anteriormente en el testamento. 
libres o esclavos, de quien no tiene más hacienda ni qué pagar, y esclavos con limosnas de sus amos. Y la iglesia -prosigue- es de la advocación de los Reyes Magos, conforme a los que allí se curan, y como se llama casa de Desamparados cúranse también allá españoles que no quieren recibir en otros hospitales, pues son desamparados, y porque el nombre confirme con el hecho tengo en el dicho hospital un torno donde se reciben niños huérfanos desamparados de sus madres, los cuales se crían algunos a costa de la casa y otros crían personas de caridad gratis $[\ldots]{ }^{\prime 28}$

En esta declaración se puede observar, en primer término, el fervor cristiano de López. Dejando aparte la fundación de la casa cuna, los principales destinatarios del hospital son: mestizos, mulatos y negros libres o esclavos, siempre que sean indigentes, y esclavos pagados por los amos. La documentación del Cabildo de la ciudad de México lo describe el 12 de marzo de 1582 como un "hospital de negros, mulatos y mestizos libres", ${ }^{29}$ o como un "hospital de negros o negras libres e mestizos e mulatos libres e indios" el 20 de agosto de ese mismo año. ${ }^{30}$ En una relación de los hospitales de la ciudad de 1583 se dice que en el de los Desamparados había "negros, mulatos y mestizos pobres y libres que no tienen quien los cure", ${ }^{31}$ observándose que la categoría de personas libres es la que predomina.

También en la licencia de Moya de Contreras se lee que en la ciudad y comarca de México había muchos "mulatos y negros libres que cuando se enferman no tienen en donde se poder curar" al no encontrar lugar en los hospitales existentes. "De cuya causa muchos mueren por falta de cura y remedio necesario, y lo que peor es, sin confesar ni recibir los demás sacramentos, y el doctor Pedro López, vecino de esta ciudad nos ha hecho relación que, movido a caridad y compasión de los susodichos, tiene tratado de fundar un hospital para el dicho efecto, que se nombre e intitule el Hospital de los Desamparados". ${ }^{32}$

En el ya citado testamento, López declara que en los Desamparados hay un mobiliario humilde que fue comprado gracias a limosnas y se cui-

28 AGNM, Tierras, vol. 3.556, exp. 4, f. 38r; Posteriormente a mi investigación, el documento ha sido publicado en Ferreiro - Sigaut, Testamento, págs. 189-191.

29 Libro octavo de Actas de Cabildo, que comenzó en 29 de octubre de 1571 y terminó en fin de diciembre de 1584, Imprenta y Librería de Aguilar e Hijos, México 1893, pág. 548.

30 Ibídem, pág. 572.

31 "Relación de los hospitales de la ciudad y del arzobispado de México, hecha por orden del Arzobispo Don Pedro Moya de Contreras, México, 4 de abril de 1583”, en Cuevas, Documentos inéditos, pág. 326.

32 AGNM, Tierras, vol. 3.556, exp. 4, f. 1r. 
da la comida lo mejor posible. Por lo que respecta a la atención espiritual, se celebra misa al menos los días de fiesta y los domingos. También habla de los estipendios que da a los sacerdotes de la Vera Cruz, y de los ornamentos que se usan en las funciones litúrgicas.

Una vez fundado el hospital, el doctor Pedro López instituyó una cofradía entre personas devotas e influyentes, que recibió el nombre de Nuestra Señora de los Desamparados. La cofradía dedicaba sus esfuerzos a la recogida y cuidado de los niños abandonados y para ellos constituyó una casa cuna. La capacidad era de veinte a treinta camas, sin contar los expósitos. ${ }^{33} \mathrm{El}$ hospital se mantenía de limosnas y de bienes del fundador. ${ }^{34}$

Un documento que nos da nueva luz sobre esta fundación es una información que mandó hacer en abril de 1591 el doctor Pedro López, con objeto de conseguir de la Santa Sede indulgencias y gracias espirituales para el hospital. Fueron llamados a testificar tres frailes de la Merced, dos curas de la parroquia de la Vera Cruz, el sacristán de la parroquia y dos vecinos del barrio de la Vera Cruz. En la cuarta pregunta de la información se les cuestionaba lo siguiente:

"Ytem si saben que asimismo en el dicho Hospital de Desamparados se curan todos los mulatos y negros libres que, por estar sin amos e destituidos de todo favor, y pobres en sumo grado, que era ocasión de no ser curados e morir sin sacramentos, el dicho hospital, acudiendo a los tan desamparados, los cura y provee de todo lo necesario, digan que saben". ${ }^{35}$

Los distintos testigos avalan cuanto es dicho en esta pregunta. El padre fray Mateo García afirma que en Desamparados se asistían muchos "negros y mulatos libres" y "los curan al presente con muy grande cuidado y solicitud, proveyéndolos de todo lo necesario, y los tienen allí hasta que tienen salud para poder trabajar e ir a buscar su vida". ${ }^{36}$ Uno de los

33 Con posterioridad a la muerte del fundador, su hijo Jusepe López informa que "de ordinario hay de veinte a treinta y más enfermos, hombres y mujeres". Véase Un desconocido cedulario del siglo XVI perteneciente a la catedral metropolitana de México, prólogo y notas de Alberto María Carreño, Ediciones Victoria, México, 1944, pág. 392. Cfr. también Muriel, Josefina: Hospitales de la Nueva España, Universidad Nacional Autónoma de México/Cruz Roja Mexicana, México 1990, vol. I, pág. 260.

34 En el testamento se hace referencia a que el hospital "tiene al presente dos mil pesos echados a censo sobre los portales de la plaza y otros setecientos sobre casas de Diego de Ludueña Maldonado"; AGNM, Tierras, vol. 3.556, exp. 4, f. 38v; Ferreiro - Sigaut, Testamento, pág. 193. Muriel aporta otros datos sobre la base económica del centro en Hospitales, vol. I, pág. 260.

35 AGNM, Tierras, vol. 3.556, exp. 4, f. 4r.

36 Ibidem, f. 5v. 
beneficiados de la Vera Cruz, Juan Zugarte de La Cruz, apunta que los mulatos y negros libres reciben "los santos sacramentos y los entierran en él y los proveen de todo lo necesario" ${ }^{37} \mathrm{El}$ otro sacerdote de la parroquia, Nicolás Morales, añade que él mismo "ha administrado a muchos negros y mulatos pobrísimos, que si no les hubieran caridad en el dicho hospital murieran, y por ser muy pobres sin recibir los sacramentos, y así los ha visto curar, proveídos de todo lo necesario de medicinas y sustento corporal y espiritual". ${ }^{38}$

El escribano real Francisco Sánchez, vecino del barrio, afirma que, de no ser por la fundación del Hospital, muchos de estos negros y mulatos morirían sin recibir los sacramentos y añade: "por su barbaridad de ellos y no tener ánimo ni entendimiento para procurar lo a esto tocante". ${ }^{39} \mathrm{O}$ sea, que en su opinión los negros y mulatos libres no podían de ninguna manera organizarse ellos mismos para proveer a su propia salud espiritual y material. El último testigo, el vecino Marcos de Vargas, español, añade que "según las obras de caridad espiritual y corporal que se hacen el dicho hospital, no alcanza para ello las limosnas que hacen los fieles cristianos". ${ }^{40} \mathrm{De}$ hecho parece que las finanzas de este hospital no eran tan regulares como las de San Lázaro. ${ }^{41}$

Recapitulando, en el hospital de los Desamparados encontraban las puertas abiertas, como última tabla de salvación, todos aquellos que no tenían acogida en los otros hospitales. Lo cual no obstaba para que se defendiera la idea de que los principales pacientes debían ser los mestizos, mulatos y negros libres, es decir, las categorías sociales que por entonces no tenían un hospital propio. A propósito de esta fundación de López, Josefina Muriel comenta: "nos muestra una vez más ese rasgo distintivo del doctor López, que fue la eficacia de su caridad. Sus obras brotaron siempre tras el conocimiento vivo de la realidad social y por ende de las necesidades más apremiantes de nuestro pueblo". ${ }^{42}$

Veamos ahora la acción evangelizadora de Pedro López hacia los negros en dos memoriales enviados a los padres reunidos en el Tercer Concilio Mexicano de 1585.

37 Ibidem, f. $11 \mathrm{v}$.

38 Ibidem, f. 16r.

39 Ibidem, f. $18 \mathrm{v}$.

40 Ibidem, f. $21 \mathrm{v}$.

41 Greenleaf, "Padre de los pobres”, págs. 268-269.

42 Muriel, Hospitales, vol. I, pág. 259. 


\section{Los memoriales sobre negros de Pedro López presentados ante los padres del Tercer Concilio de México $(\mathbf{1 5 8 5})^{43}$}

Cuando en esa fecha se celebró en la capital de la archidiócesis mexicana el Tercer Concilio Provincial, Pedro López, por entonces de edad en torno a los cincuenta y ocho años, era un personaje muy conocido y respetado en la ciudad de México. Dirigió cinco memoriales a los padres conciliares, siendo la persona, junto con el catedrático de la Universidad Ortiz de Hinojosa, que más escritos envió. Pues bien, de esos cinco textos, dos tratan específicamente de la atención de las personas de raza negra de la ciudad de México. El primero de éstos fue leído en el aula conciliar el 25 de enero de 1585, sólo cinco días después de la solemne apertura, y el segundo fue examinado el 9 de abril. El objetivo de ambos era la creación de una cofradía de negros para atender espiritualmente a la población africana. Sus datos y argumentos son muy interesantes por la visión que ofrecen del negro mexicano. El primer memorial se lamenta por "la falta de doctrina y cristiandad que tienen los negros en esta tierra; lo uno, por falta de sus amos y culpa; lo otro, por la de los mismos negros, por lo cual tienen más necesidad de ayuda". ${ }^{4}$

Ya aquí el doctor López pone el dedo en una de las llagas del mundo mexicano, la falta de evangelización de los negros. ${ }^{45}$ considerando que en una sociedad cristiana no podía concebirse pacíficamente un grupo social no evangelizado. Y que los negros eran objeto de educación religiosa nadie, en teoría, lo podía negar pues, como hemos visto, varias reales cédulas lo preceptuaban. Pero la realidad percibida por nuestro doctor era que los amos, en términos generales, no se preocupaban de la formación cristiana de sus esclavos. ${ }^{46}$ Además, esa formación no era nada sencilla, y

43 Una primera aproximación a esta cuestión en Martínez Ferrer, Luis: "El doctor Pedro López y la catequización de los negros de la ciudad de México. El 'memorial suelto' del doctor López al Tercer Concilio de México (1585)”, Mar Oceana, 11/12, Madrid, 2002, págs. 209-217.

44 MM, 268, fol. 238r; Carrillo Cázares, Manuscritos, pág. 429.

45 Aunque sin cuestionar en lo más mínimo la trata, cosa que era entonces prácticamente impensable. Se daban casos, como el de López, de atención humana y cristiana de las personas de color, pero no de cuestionamiento de la institución de la esclavitud. Ya en el siglo XVII encontramos personajes que se atreven a criticar valientemente la misma existencia de la esclavitud. López García, José Tomás: Dos defensores de los esclavos negros en el siglo XVII: Francisco José de Jaca, OFM Cap, y Epifanio de Moirans, Universidad Católica Andrés Bello, Caracas, 1981.

46 Sus intereses eran probablemente económicos. Los africanos eran fuertes: "un negro hace el trabajo de cuatro indios", se decía, y se les consideraba indispensables para la floreciente explotación minera. 
los dueños de éstos, en general, no parecían estar dispuestos a esmerarse en la catequesis.

Pero también los propios negros, en palabras de López, eran en parte culpables, como afirma a continuación el memorial: "Aunque religiosos procuran de doctrinarlos y catequizarlos y que oigan misa y sermón, no pueden, a causa de no haber entre ellos ladinos caritativos que entiendan en este ministerio y tengan cuenta de hacerlos ir a la iglesia y tengan doctrina y confiesen y reciban los santos sacramentos". ${ }^{47}$ Es decir, que debían ser los negros ladinos cristianos, conocedores del castellano y más habituados a la compleja sociedad novohispana, los que debían tomar la iniciativa de fomentar la vida cristiana entre sus congéneres. Esta es la intuición de López, y es por ello que va a postular inmediatamente en el memorial la creación de una cofradía de negros.

"Por lo qual, movido de caridad, he pensado un medio, si vuestra señoría ilustrísima lo tiene por bueno, y es que, entre los de sus tierras y aun entre los muy ladinos criollos, se elijan algunos quincuagenarios (...) como pareciere, buenos cristianos, que los hay, y éstos se encarguen de que los cristianos oigan (en) las fiestas misa por la mañana y sermón a la tarde, que se dará orden que le haya para ellos, y confiesen a lo menos la cuaresma y comulguen los que tuvieren para ello talento, y los amancebados se casen y se quiten de otros vicios". ${ }^{48}$

Hasta aquí los deseos del doctor se dirigen hacia los negros bautizados, aplicando a sus necesidades los métodos pastorales ordinarios. Y todo apoyado en la labor de estos ladinos, que vendrían a ser una suerte de "fiscales" destinados a apoyar a los ministros sagrados en su labor.

En cuanto a los no bautizados, la cofradía serviría — dice el memorial- para que les

"hagan catequizar y bautizar, teniendo cada uno de estos ladinos minuta de los que son a su cargo, y creo éstos harán en sus naturales más impresión para atraerlos a esto, que religiosos. Y para ponerse esto en efecto y animar a los ladinos y bozales para lo dicho, será necesario que vuestra señoría dé licencia y mande que se instituya una cofradía o hermandad de negros en esta ciudad de México, como hay en Sevilla, y en Lisboa, y en la ciudad de los Ángeles". ${ }^{9}$

47 MM, 268, fol. 238r; Carrillo Cázares, Manuscritos, pág. 429.

48 Ibidem.

49 Ibidem. 
Bien estaba al tanto el doctor López de que en Sevilla ya existía una hermandad de negros. En efecto, a finales del siglo XIV se creó en esa ciudad una casa-hospital y una hermandad para africanos ${ }^{50}$ y si se examinan sus reglas de 1553 se observa que cumplen los objetivos que pretendía Pedro López en el memorial que estamos comentando: en el capítulo 19 los cofrades son obligados a acudir a "tres fiestas generales con toda solemnidad y sermón, las cuales se han de hacer y cantar". ${ }^{51}$ En cuanto a los contactos de Pedro López con la ciudad del Betis, sabemos que con referencia a su hospital de San Lázaro, había pedido el envío de las reglas y privilegios del homónimo sevillano. ${ }^{52}$

Respecto a la cofradía de esclavos negros o pretos en Lisboa, sabemos que desde el último cuarto del siglo XV sus miembros formaban parte de "confrarias" e "irmandades", compuestas mayoritariamente por blancos, en calidad de irmãos. La primera de las hermandades de la ciudad de Lisboa fue la de la iglesia del convento de santo Domingo donde, a partir del siglo XVI, los esclavos, cada vez más numerosos, conseguirían elegir algunos de ellos para la Mesa de la hermandad". ${ }^{33}$ Es muy posible que López conociera la existencia de esta cofradía lisboeta a través de sus muchas amistades en la comunidad de dominicos de la ciudad..$^{54}$

Por lo que respecta a la cofradía de negros de Puebla de Los Ángeles, hay datos acerca de una Congregación para mulatos, fundada por los jesuitas en 1580. ${ }^{55}$ Sin embargo, si a esta institución se refiere López en su memorial, no es exactamente una cofradía, sino una vinculación de congregantes con fines exclusivamente espirituales, mientras que la cofradía presuponía, junto con los religiosos, aspectos sociales y económicos muy importantes. En la documentación que he podido consultar, procedente del

50 Moreno Navarro, Isidoro: La antigua Hermandad de los negros de Sevilla. Etnicidad, Poder y Sociedad en 600 años de Historia, Universidad de Sevilla/Consejería de Cultura de la Junta de Andalucía, Sevilla, 1997, pág. 36.

51 Ibidem, pág. 65.

52 Archivo de Protocolos de Sevilla, Oficio 1, año 1560, vol. 2, f. 503. Referencia en Moreno Toral, Esteban: Estudio social y farmacoterapéutico de la lepra: el Hospital de San Lázaro de Sevilla (ss. XIII-XIX), Diputación Provincial de Sevilla, Sevilla, 1997, pág. 101.

53 Trinidade, Laura y Antonio Manuel Dias Diogo: "As irmandades de escravos e forros", en Rodríguez, Ana Maria (coord.): Os negros em Portugal - sécs. XV a XIX, Comissão Nacional para as Comemorações dos Descobrimentos Portugueses, Lisboa, 1999, pág. 129. Traducción nuestra.

54 Sobre las excelentes relaciones de Pedro López con la comunidad dominica de México, véase, Franco, Fray Alonso: Segunda parte de la Historia, lib. 1, cap. 37, págs. 139-140.

55 Palomera, Esteban: La obra educativa de los jesuitas en Puebla (1578-1945), Universidad Iberoamericana/Instituto Oriente/Benemérita Universidad Autónoma de Puebla, México, 1999, págs. 197-198. 
Archivo Histórico de Puebla, no hay menciones a ninguna cofradía de negros. ${ }^{56}$

Lo que sí está claro es la percepción de Pedro López de que no había cofradía de negros en la ciudad de México, pues afirma en el memorial que comentamos: "cosa que nunca en México se ha intentado, por temor que de estas juntas y congregaciones ha de resultar alguna rebelión o alzamiento", ${ }^{57}$ o para evitar que en sus bailes no se cometan "ofensas de Dios". Era consciente del gran miedo de las autoridades a que las reuniones de negros fueran ocasión de graves disturbios públicos.

Sobre esta petición de Pedro López debemos mencionar también la difícil cuestión de cuándo se creó una cofradía de morenos y morenas en la ciudad de México. Según Lourdes Mondragón, en 1560 fue fundada una cofradía de esclavos negros, intitulada de San Nicolás de Tolentino y asentada en la iglesia de la Vera Cruz. ${ }^{58}$ Por otro lado, Alicia Bazarte Martínez y Clara García Ayluardo afirman que la primera cofradía de morenos y morenas de la ciudad de México se estableció en la iglesia de Santa María la Redonda, que posteriormente cambió su sede junto a la capilla de Santo Domingo de México, y finalmente quedó radicada en la parroquia de la Santa Vera Cruz. Aportan un documento con una aprobación papal de la cofradía en 1571, citado en una patente de indulgencias impresa en México en 1727. Se hacen extensivas las indulgencias de la cofradía de México a las cofradías homónimas de Michoacán y Oaxaca. ${ }^{59}$

Pudiera ser que estas traslaciones tuvieran que ver con la actividad de López en el convento dominico y después con la existencia del Hospital de los Desamparados, pared con pared con la parroquia de la Santa Vera Cruz. En cualquier caso, sí hay constancia documental de que en 1571 el papa Pío V aprobó y concedió indulgencias para la Cofradía de los Morenos y Morenas del Derramamiento de la Sangre de Cristo, con sede en el Convento Imperial de Santo Domingo; además otro pontífice, Clemente VIII, concedió indulgencias a la cofradía de morenos y morenas de la ciu-

56 Cfr. Disco Compacto Actas de Cabildo: Ayuntamiento de Puebla (1996-1999), Actas de Cabildo de los siglos XVI y XVII de la Ciudad de la Puebla de los Ángeles, Ayuntamiento de Puebla Universidad de Colima, 1997.

57 MM, 268, fol. 238r; Carrillo Cázares, Manuscritos, pág. 429.

58 Mondragón Barrios, Esclavos, pág 58. No hemos encontrado otros datos sobre esta fundación.

59 Bazarte Martínez, A. y García Ayluardo, C.: Los costos de la salvación. Las cofradías y la ciudad de México (siglos XVI al XIX), CIDE-Instituto Politécnico Nacional/Archivo General de la Nación, México, 2001, pág. 322. 
dad de México, con la advocación de San Benito de Palermo, santo típico de la devoción de los africanos (él mismo hermano lego franciscano de origen etiópico, que vivió en Palermo entre 1526 y 1589), y radicada en Santa María la Redonda. ${ }^{60}$

Estos datos indicarían que esa cofradía de San Benito nació en 1599 en forma independiente de la aprobada por Pío V en 1571, bajo la órbita franciscana. ${ }^{6}$ Concordando con este aserto, Josefina Muriel afirma que en 1570 se había establecido en el Hospital de la Concepción de Nuestra Señora (luego Hospital de Jesús), una "hermandad de negros bozales, que anteriormente se hallaba establecida en la iglesia de Santo Domingo". ${ }^{62}$ Los negros ocupaban allí la capilla de Santa Efigenia y en 1577 se vieron amenazados por la Congregación de sacerdotes de San Pedro, fundada en ese mismo año. ${ }^{63}$ Los clérigos congregantes se asentaron también en la capilla de Santa Efigenia y pusieron en ella una imagen de San Pedro, por lo que los negros, temerosos de que fueran finalmente expulsados de su capilla, decidieron sacar la imagen de San Pedro y depositarla en la calle ${ }^{64}$ De todo esto lo que cabe deducir, para nuestro propósito, es que si en 1585 Pedro López afirma que no había una cofradía de negros en la ciudad, quizás es que las cofradías citadas, nacidas en 1560 o 1577, para 1585 ya habían dejado de existir o que, por razones desconocidas, no tenía en cuenta la referida cofradía de bozales.

En el memorial que comentábamos Pedro López explicaba que en la ciudad de México nunca se había intentado crear una congregación de negros por miedo a problemas de alzamientos pero "(...) nunca resultó tal rebelión cuanto más que no han ellos de hacer junta, sin estar presentes uno o dos españoles, por vuestra señoría diputados para que asistan a ella" ${ }^{65}$ En contra de su opinión, lo cierto es que las crónicas nos hablan de al menos tres rebeliones de negros en Nueva España anteriores a 1585: una en 1537,

60 Así lo demuestra una patente de indulgencias de la cofradía, de 1726. Agradecemos a la doctora Alicia Bazarte la gentileza de habernos proporcionado este documento.

61 Como señala Vetancourt, el traslado de la cofradía de Santa María de la Redonda al convento de San Francisco se operó el 22 de febrero de 1633; Vetancourt, Agustín de: Teatro Mexicano, Porrúa, México, 1982, pág. 36.

62 Muriel, Hospitales, vol. I, pág. 47.

63 Otro autor llama a esta capilla la de La Escuela, dentro de la iglesia del hospital, la misma donde en 1570 se fundó una cofradía de bozales; véase Gascón Mercado, Julián: Breve historia del Hospital de Jesús, Vertiente Editorial, México, 1985, pág. 77.

64 Muriel, Hospitales, vol. II, pág. 123.

65 MM, 268, fol. 238r; Carrillo Cázares, Manuscritos, págs. 429-430. 
aunque parece que fue sólo una falsa alarma, que se solventó con la eliminación de algunos sospechosos; otra en 1546, donde los cabecillas fueron ahorcados en la Plaza Mayor; y la tercera en 1549, que acabó también con el ajusticiamiento de los cabecillas. ${ }^{66}$

Pero nada de esto arredraba a López, que terminaba el memorial confiando en que se podría fundar enseguida la cofradía, y que en

"la dominica in albis, ${ }^{67}$ como se solía hacer en la primitiva Iglesia, se llevasen a bautizar a la iglesia gran cantidad de negros, y que quedasen pocos sin bautismo, adultos, hasta que viniese de Castilla otro navío de negros, y los cristianos confesasen todos o casi esta cuaresma, y quedaría esta costumbre perpetua en que aquel día se llevasen a la iglesia todos los catecúmenos a bautizar". ${ }^{68}$

Como se ve, el doctor López hacía planes a corto y a largo plazo. Deseaba que ya en la cuaresma de 1585 casi todos los negros de la ciudad cumpliesen con el precepto pascual, y pasado el tiempo, que fuese un día especial para que los negros se bautizaran en esa misma iglesia.

Al finalizar el memorial descubre explícitamente su visión cristiana de las personas de raza negra: su petición iba enderezada "al servicio de Dios Nuestro Señor y provecho de estas ovejas por quien murió, y ovejas que no tiene vuestra señoría otras que más necesidad tengan de remedio que estos negros". ${ }^{99}$ Lejos de ver a los africanos como mera fuerza de trabajo y, al mismo tiempo, una peligrosa amenaza para el orden social, López los considera simplemente como los más necesitados de ayuda espiritual, por quienes valía la pena encontrar algún medio que facilitara su efectiva evangelización, como cristianos que eran o debían ser. Lo importante era eso, y la cofradía sólo un medio para lograrlo, como dice al pedir, despidiéndose del obispo "conceda mi petición siendo idóneo este medio que propongo (la cofradía), y si no fuese tal, vuestra señoría reciba mi voluntad y provea de otro, porque estos pobres negros se remedien". ${ }^{70} \mathrm{El}$ memorial fue leído en el aula conciliar el 26 de enero de 1585.

Aún hubo un segundo memorial de este doctor Tercer Concilio Mexicano sobre los africanos. Fue leído en el aula conciliar el 9 de abril, y en él torna a pedir una cofradía de negros. Se relatan los intentos del

\footnotetext{
66 “Negros, conspiraciones de”, en Diccionario Porrúa, pág. 2453.

67 Primer domingo tras el domingo de pascua.

68 MM, 268, f. 238v; Carrillo Cázares, Manuscritos, pág. 430.

69 Ibidem.

70 Ibídem.
} 
galeno por organizar sermones durante la cuaresma de 1585, a través del padre dominico fray Juan Ramírez. Veamos la parte central de este nuevo memorial:

“...porque esta cuaresma, ${ }^{71} \sin$ haber este medio (sin cofradía) yo procuré que tuviesen en el hospital de Desamparados sermón las fiestas, y el primero domingo ${ }^{72}$ se juntaron algunos y les predicaba la doctrina el padre fray Juan Ramírez y luego aflojaron, que el cuarto domingo ${ }^{73}$ apenas había a quién enseñar, y esto por falta de la dicha cofradía, porque con ella unos a otros se habían de llamar y convocar". ${ }^{74}$

Estas líneas denotan nuevamente la religiosidad de López que, aún sin cofradía, se había ocupado personalmente de organizar sermones cuaresmales en su propio hospital, donde sabemos que se curaban muchos negros y mulatos. Pero el resultado había sido un tanto decepcionante y por ellos insistía el médico en porfiar por la cofradía ante los padres del Concilio. Incluso se atrevía a terminar su petición escribiendo: "Y advierto a vuestras señorías que tengo de juntar chichimecos con los dichos negros, no menos necesitados que ellos". ${ }^{75}$ Su preocupación por los desamparados se extendía ahora a un nuevo colectivo, el de los indios rebeldes del Norte mexicano.

Con todo, la respuesta del Concilio fue contundente; a continuación del memorial, el secretario conciliar, Juan de Salcedo, escribió: "a 9 de abril de 1585. Que se oye. No ha lugar". No podemos pensar que los padres conciliares desestimaran la desinteresada petición del doctor López por superficialidad. Cualquiera que haya estudiado la documentación sobre el Tercer Concilio Mexicano comprueba la profesionalidad y tesón con que trabajaron los conciliares, en particular Juan de Salcedo y algunos obispos y peritos. ${ }^{76}$ Tampoco se trataba de cuestiones personales contra López, pues observamos las anotaciones que hicieron a otros memoriales suyos, requiriéndole ulteriores informaciones, por ejemplo en uno sobre cuestiones

71 En el año 1585, en Nueva España, donde regía ya el calendario Gregoriano, la cuaresma empezó el 6 de marzo (miércoles de ceniza).

7210 de marzo.

7331 de marzo.

74 MM, 268, f. 233r; Carrillo Cázares, Manuscritos, pág. 417.

75 Idem e Ibidem, pág. 418.

76 Sobre esta cuestión, véase, Galindo Bustos, Jesús: El aparato de fuentes del Concilio Tercero de México, Universidad Pontificia de la Santa Cruz, Tesis Doctoral en Teología, Roma 2003, pro manuscripto. 
económicas. ${ }^{77}$ Sencillamente, los padres conciliares consideraban improcedente la fundación de una cofradía de negros en México.

Muy probablemente la presión externa del Cabildo civil de la ciudad influyó poderosamente en la negativa. Concretamente, el gobierno local de la capital mexicana se opuso frontalmente a esa medida. En una de las actas de los regidores, con fecha 20 de mayo de 1585, se lee la resolución "que el señor don Diego de Velasco como comisario con el concilio, sepa si se ha pedido que los negros no tengan cofradía ni junta de posesión, y si no lo ha pedido que se pida en el concilio que se mande con mayor gravamen". ${ }^{78}$

Quizás también el párrafo final relativo a los chichimecos en el último memorial acabó por decidir a los obispos a favor de la negativa. Si ya las personas de raza negra y sus reuniones eran consideradas peligrosas, aún más lo serían si se mezclaba esta cuestión con la de los chichimecos y la guerra, que había provocado muy concienzudos debates en el concilio, como ha estudiado Carrillo Cázares. ${ }^{79}$ Por si fuera poco, existían también pequeños grupos de negros cimarrones que atacaban los caminos principales de la Nueva España y fue de particular importancia la memorable rebelión del negro Nyanga, que, en la región entre Orizaba y Córdoba, mantuvo en jaque a las poblaciones estables del centro-oriente de la Nueva España hasta los inicios del s. XVII. ${ }^{80}$ Es por eso comprensible que el Concilio se pronunciara negativamente respecto de la cofradía de negros, pues probablemente pensaban que supondría una fuente de inseguridad pública en la sociedad mexicana, ya suficientemente crispada por la guerra chichimeca y conocedora, por otro lado, de la peligrosidad de los negros cimarrones.

Desde otro punto de vista, no sabemos hasta qué punto esta petición de López pudo influir en la legislación del Tercer Concilio Mexicano sobre la atención pastoral de los negros y mulatos. Si examinamos los decretos, los esclavos negros son contemplados entre la categoría de "rudos", a los

77 MM, 268, f. 362v; Carrillo Cázares, Manuscritos, págs. 707-708.

78 Libro noveno de Actas, pág. 26. El alguacil mayor Diego de Velasco era comisario del Cabildo en el Concilio desde el 13 de mayo de 1585, fecha en la que sustituyó a Juan Velázquez de Salazar.

79 Carrillo Cázares, Alberto: El debate sobre la Guerra Chichimeca, 1531-1585, El Colegio de Michoacán/El Colegio de San Luis, Zamora, Mich.- San Luis Potosí, 2000, págs. 321-402 y 679-721.

80 Después de cuarenta años de rebeliones, el movimiento de Nyanga culminó en 1608 con la fundación de un pueblo de negros cimarrones, "el primer pueblo libre de América". Aguirre Beltrán, Gonzalo: "Nyanga y la controversia en torno a su reducción a pueblo", en el mismo autor: Obra antropológica, vol. XVI, El negro esclavo en la Nueva España, Fondo de Cultura Económica, México, 1994, págs. 179-186. 
que hay que catequizar y procurar que se le administre el bautismo; ${ }^{81}$ deben tener una instrucción adecuada para poder recibir la Eucaristía ${ }^{82}$ y sus amos les tienen que facilitar la asistencia a la misa dominical, ${ }^{83}$ debiendo ser tratados con más suavidad que los españoles y mestizos en el caso de que no cumplan con el precepto pascual; ${ }^{84}$ tienen el derecho a recibir la unción de enfermos en sus casas, ${ }^{85}$ y no se les puede impedir que contraigan matrimonio libremente y que hagan vida marital sin sufrir separaciones entre los cónyuges. ${ }^{86}$ Quizás el decreto que toca más la temática abordada por López en sus dos memoriales sea el referente a que los amos no pueden impedir que sus esclavos adultos acudan a recibir instrucción doctrinal previa al bautismo; y así finaliza el decreto con estas palabras: "Y los amos de los esclavos que han de ser bautizados, sean obligados a mandarlos al lugar señalado por el obispo, para ser allí instruidos en los principios de la fe cristiana" ${ }^{87}$ Era esto precisamente lo que López deseaba con la cofradía: crear un ámbito idóneo en que los negros pudieran recibir su catequesis, pero el Concilio se pronunció negativamente, como hemos visto.

Queda en pie una figura de notable espesor. En medio de las tensiones y contradicciones sociales mexicanas de fines del siglo XVI, López supo salir del círculo de sus propios intereses personales para preocuparse de los "últimos", guiado por una conciencia modelada por la doctrina de la Iglesia católica.

Recibido el 11 de octubre de 2007 Aceptado el 22 de septiembre de 2008

81 SANCTUM provinciale concilium Mexici celebratum anno Domini millessimo quingentessimo octuagessimo quinto prasidente in eo Illmo. ac Rmo. D. D. Petro Moya de Contreras, archiepiscopo mexicano Roma confirmatum die vigessimo septima octobris anno 1589, nunc vero ad instantiam et sumptibus Illmi. ac Rmi. Ioannis de la Serna, archiepiscopi mexicani iussu regio editum, Apud Joann. Ruíz Typographum, México 1622, [III Mex], Lib. I, tit. 1, De Doctrina Christiana rudibus tradenda, $\S \S \mathrm{I}, \mathrm{III}, \mathrm{VI}, \mathrm{VII}$.

82 III Mex, Lib. III, tit. 2, De administratione Sacramentorum, § III. También el catedrático de la Universidad de México Fernando Ortiz de Hinojosa (1530-1597) se había ocupado de la cuestión de la recepción de la Eucarística de los negros en un memorial al Tercer Concilio. Cfr. "Advertencias del doctor Ortiz de Hinojosa", en Llaguno, José Antonio: La personalidad jurídica del indio y el III Concilio Provincial Mexicano (1585), Porrúa, México, 1963, pág. 211. Original del memorial en MM 268, fol. 226.

83 III Mex, Lib. II, tit. 3, De feriis, § V.

84 III Mex, Lib. III, tit. 2, De vigilantia, et cura circa subditos, praesertim in sacramentorum receptione, $\S \S \mathrm{III}-\mathrm{V}$.

85 III Mex, Lib I, tit. 6, De Sacra unctione, §§ IV-V.

86 III Mex, Lib. IV, tit. 1, De sponsalibus et matrimoniis, § VIII-IX; Lib. V, tit. 12, De poenitentiis et remissionibus, Excommunicationes quoque latae sententiae ab hac synodo statutae, quarum absolutio episcopo reservatur, sunt haec, § IX.

87 III Mex, Lib. III, tit. 16, De Baptismo, § IV. Original: Heri vero servi qui baptizandi sunt, eos mittere compellantur ad locum ab Episcopo deputatum, ut ibi documentis Christianae Fidei imbuantur. 